\title{
Musculoskeletal manifestations of diabetes mellitus
}

\author{
L L Smith, S P Burnet, J D McNeil
}

Br J Sports Med 2003;37:30-35

Rheumatic complaints are common in patients with diabetes. Maintaining good glycaemic control by exercise, diet, and medication improves or prevents the development of rheumatic conditions.

$\mathrm{D}$ iabetes mellitus is a chronic metabolic condition characterised by persistent hyperglycaemia with resultant morbidity and mortality related primarily to its associated microvascular and macrovascular complications. It is common, with recent estimates showing that 7.5\% of Australians over 25 have diabetes, of which $50 \%$ of cases are undiagnosed. ${ }^{1}$ Most of these patients (85\%) have type 2 diabetes mellitus. Type 1 generally starts in the young as an autoimmune mediated disease of pancreatic dysfunction, and requires lifelong parenteral insulin supplementation. Type 2 generally occurs in people over 40 and is characterised by insulin resistance.

Physical activity is an attractive treatment for patients with diabetes given its low cost, nonpharmacological nature and additional aerobic and cardiovascular benefits.

Exercise is considered to be one of the three cornerstones of optimal diabetes treatment, along with diet and pharmacotherapy. ${ }^{2}$ It is important to obtain and maintain optimal glycaemic control, as poor glycaemic control is associated with increased prevalence of diabetic complications. ${ }^{3} \mathrm{~A}$ recent meta-analysis has shown that exercise training in patients with type 2 diabetes mellitus reduces $\mathrm{HbA}_{1} \mathrm{C}$ by an amount that should decrease the risk of diabetic complications. This was not associated with an appreciably greater change in body mass in the intervention group compared with the control group ${ }^{4}$ suggesting that exercise training in patients with type 2 diabetes is valuable in its own right rather than being just an avenue to weight loss. Physical activity is therefore an attractive treatment for patients with diabetes given its low cost, nonpharmacological nature, and additional aerobic and cardiovascular benefits.
See end of article for authors' affiliations

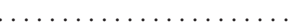

Correspondence to Miss Smith, Modbury Public Hospital, Smart Road, Modbury, Adelaide, SA 5092, Australia;

laura.smith@adelaide.edu.au

Accepted 15 August 2002
Table 1 Prevalence of musculoskeletal disorders in patients with or without diabetes

\begin{tabular}{|c|c|c|}
\hline Musculoskeletal disorder & With diabetes & Without diabetes \\
\hline Adhesive capsulitis (frozen shoulder) ${ }^{5-8}$ & $11-30 \%$ & $2-10 \%$ \\
\hline Limited joint mobility ${ }^{9-11}$ & $8-50 \%$ & $0-26 \%$ \\
\hline Dupuytren's contracture ${ }^{12-15}$ & $20-63 \%$ & $13 \%$ \\
\hline Carpal tunnel syndrome 1617 & $11-16 \%$ & $125 / 100000 *$ \\
\hline Flexor tenosynovitis $^{18}$ & $11 \%$ & $<1 \%$ \\
\hline Diffuse idiopathic skeletal hyperostosis ${ }^{10} 15$ & $13-49 \%$ & $1.6-13 \%$ \\
\hline
\end{tabular}

This review will discuss some of the musculoskeletal manifestations of diabetes mellitus. Table 1 shows the prevalence of these conditions in patients with and without diabetes. Sports physicians and patients with diabetes should be aware of these manifestations, so that optimal physiotherapy programmes can be devised that do not exacerbate existing complaints and encourage continuing physical activity in this group.

\section{FROZEN SHOULDER}

The most disabling of the common musculoskeletal problems is adhesive capsulitis, which is also known as frozen shoulder, shoulder periarthritis, or obliterative bursitis. It is characterised by progressive, painful restriction of shoulder movement, especially external rotation and abduction. ${ }^{5}$ The thickened joint capsule is closely applied and adherent to the humeral head, resulting in considerable reduction in the volume of the glenohumeral joint (fig 1). The exact origins of adhesive capsulitis are not known, although it has been associated with several other conditions, including shoulder trauma, cerebral conditions, cardiac conditions, and respiratory conditions. The natural history of the disease is characterised by three distinct phases: painful, adhesive, and resolution phases. ${ }^{5}$ Adhesive capsulitis appears at a younger age in patients with diabetes and is usually less painful, ${ }^{6}$ although it responds less well to treatment and lasts longer. ${ }^{7}$ The estimated prevalence is $11-30 \%$ in diabetic patients and $2-10 \%$ in nondiabetics. ${ }^{8-11}$ Adhesive capsulitis is associated with the duration of diabetes and age. ${ }^{1011}$

Diabetic patients with frozen shoulder are more likely to have other diabetic complications such as limited joint mobility than diabetics without a frozen shoulder, although this may be explained by age. ${ }^{1011}$

Most cases of adhesive capsulitis will resolve over time, but, in the interim, management consists of adequate analgesia and intra-articular corticosteroid injections in the painful early stages if required. Corticosteroid injections may increase blood sugar levels in diabetics over the 24-48 hour period after the injection, and 


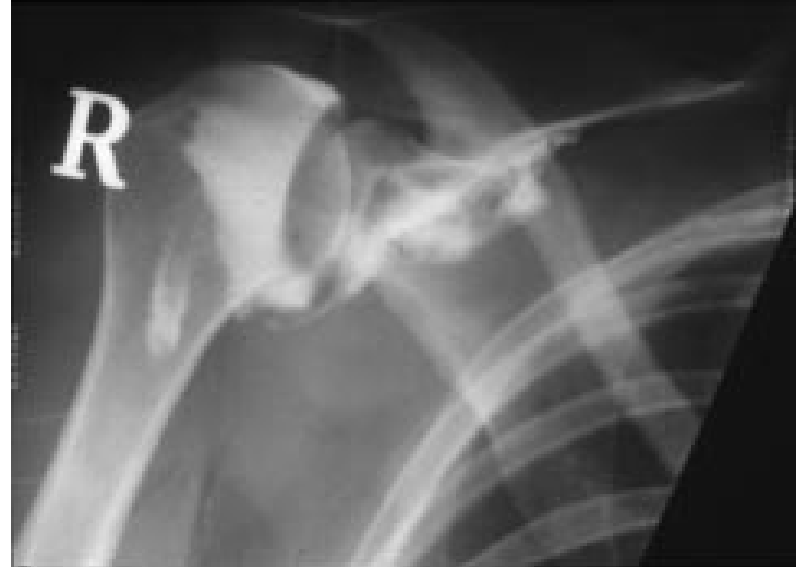

Figure 1 Shoulder arthrogram showing a contracted and adherent joint capsule in adhesive capsulitis.

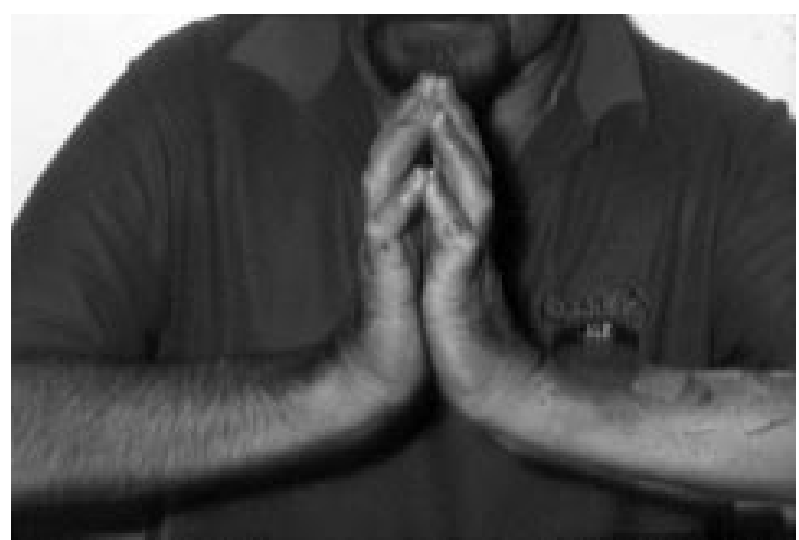

Figure 2 Limited joint mobility shown by the inability to press the two palms completely together, with the wrists maximally flexed, forming the prayer sign.

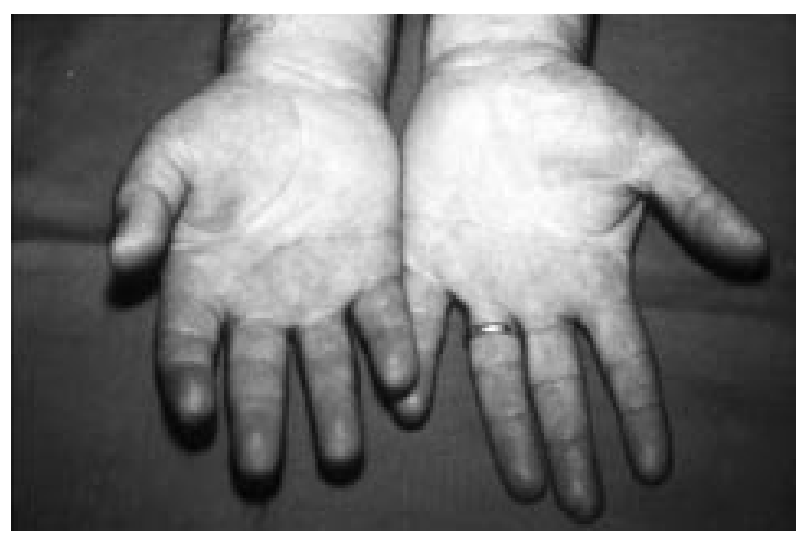

Figure 4 Hands of patient with reflex sympathetic dystrophy.

therefore blood sugar monitoring and contingency plans for elevated blood sugar levels should be considered. Distension or manipulation under anaesthesia are occasionally considered. An appropriately graded, regular physiotherapy programme should be maintained, after the painful phase, throughout the course of the condition.

\section{HAND SYNDROMES}

There is increased incidence of hand abnormalities in patients with type 1 and type 2 diabetes compared with the general population. The association between the hand abnormality and the duration of diabetes but not age or sex is a consistent finding. ${ }^{12}$

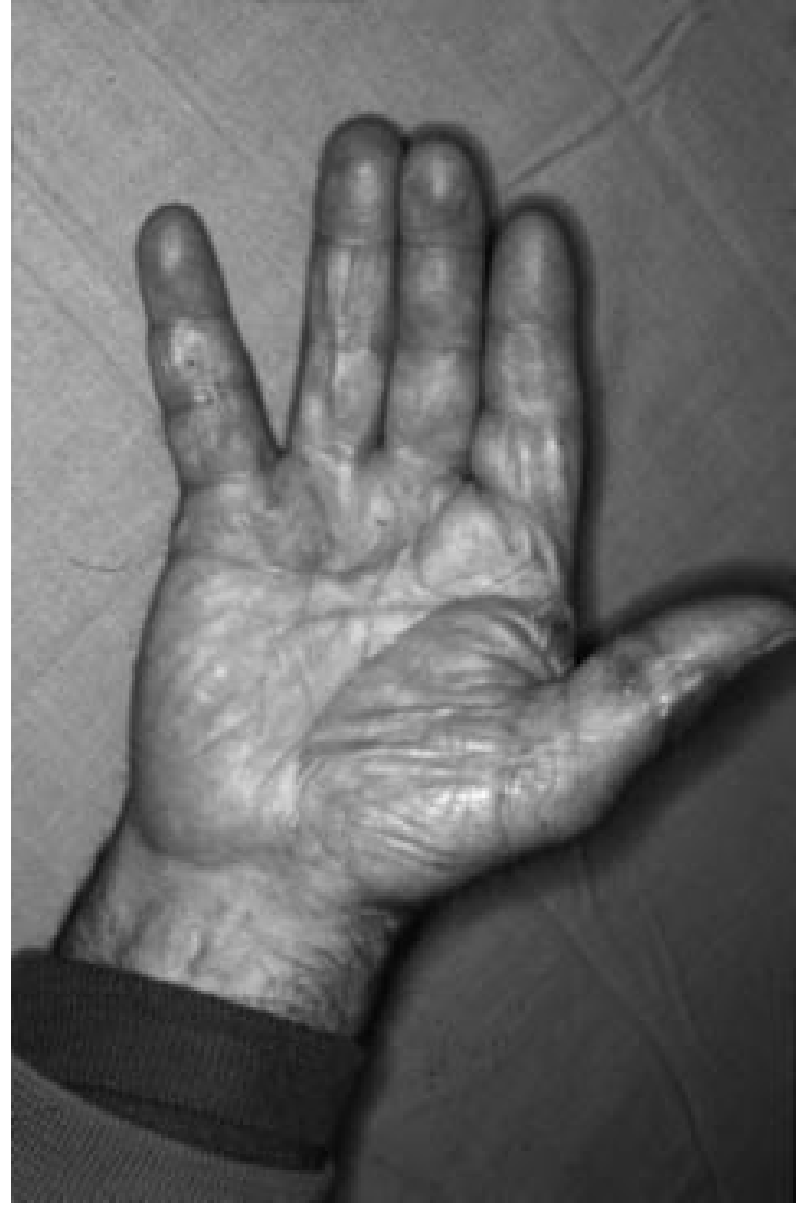

Figure 3 Dupuytren's contracture of the hand.

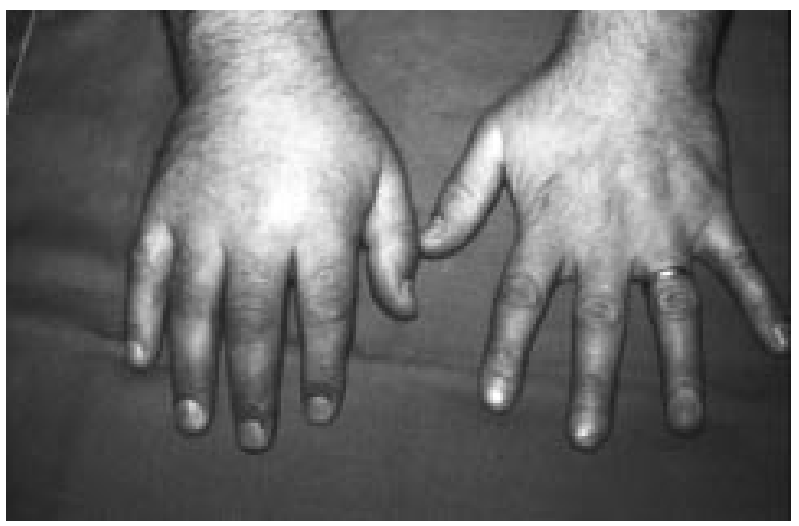

Figure 5 Hands of patient with reflex sympathetic dystrophy.

\section{Limited joint mobility}

Limited joint mobility is also known as diabetic cheiroarthopathy (after the Greek word "cheiros" for hand). It is characterised by thick, tight, waxy skin mainly on the dorsal aspect of the hands, with flexion deformities of the metacarpophalangeal and interphalangeal joints (increased resistance to passive extension of the joints). Limited joint mobility can be shown clinically by the inability of the two palms to come completely together, with the wrists maximally flexed, forming the prayer sign (fig 2). In the early stages, paraesthesias and slight pain develop. The symptoms increase very slowly, and greater pain, aggravated by movement of the hands, may supervene. Biopsy specimens of involved skin 


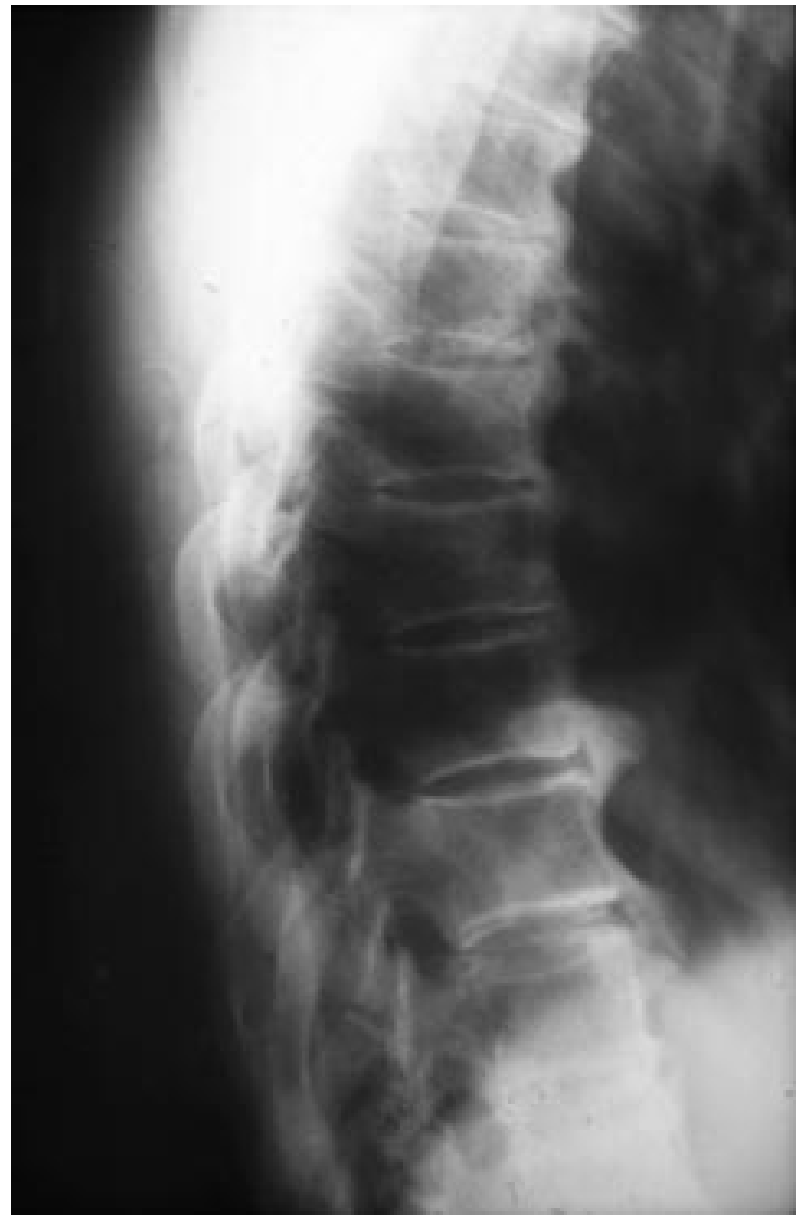

Figure 6 Radiograph (lateral view) of the thoracic spine showing flowing osteophytes in diffuse idiopathic skeletal hyperostosis.

show pronounced thickening of periarticular rather than articular collagen, which may be due to non-enzymatic glycosylation of collagen. ${ }^{13}$

This condition is most commonly seen in type 1 diabetics, with a prevalence of $8-50 \%,{ }^{6}{ }^{12}$ compared with $0-26 \%$ in controls, ${ }^{14}$ with differences in prevalence estimates possibly related to differences in the definitions used and perhaps differences in glycaemic control. ${ }^{15}$

Limited joint mobility is more prevalent in patients with diabetic neuropathy than in those without. ${ }^{16}{ }^{17}$ Limited joint mobility and Dupuytren's contracture are commonly found in the same patient. ${ }^{1218}$ Treatment consists of optimising glycaemic control and an individualised hand therapy programme if a patient's symptoms warrant it.

\section{Dupuytren's contracture}

Dupuytren's contracture is the palmar or digital thickening, tethering, or contracture of the hands (fig 3). In patients with diabetes, the ring and middle finger are more commonly affected, compared with the fifth finger in patients without diabetes. ${ }^{19}$ The prevalence of Dupuytren's contracture in diabetic patients ranges from 20 to $63 \%,{ }^{16}{ }^{19} 20$ compared with $13 \%$ in the general population. ${ }^{21}$ Among patients with Dupuytren's contracture, $13-39 \%$ have diabetes. ${ }^{1922}$ The contractures are generally milder in diabetics than in patients with Dupuytren's contracture who do not have diabetes, and the prevalence increases with advancing age. ${ }^{23}$ Treatment consists of optimising glycaemic control, physiotherapy, and hand exercises if required, and surgery only if function is severely affected. The contractures are usually mild, however, and rarely require surgery. ${ }^{6}$

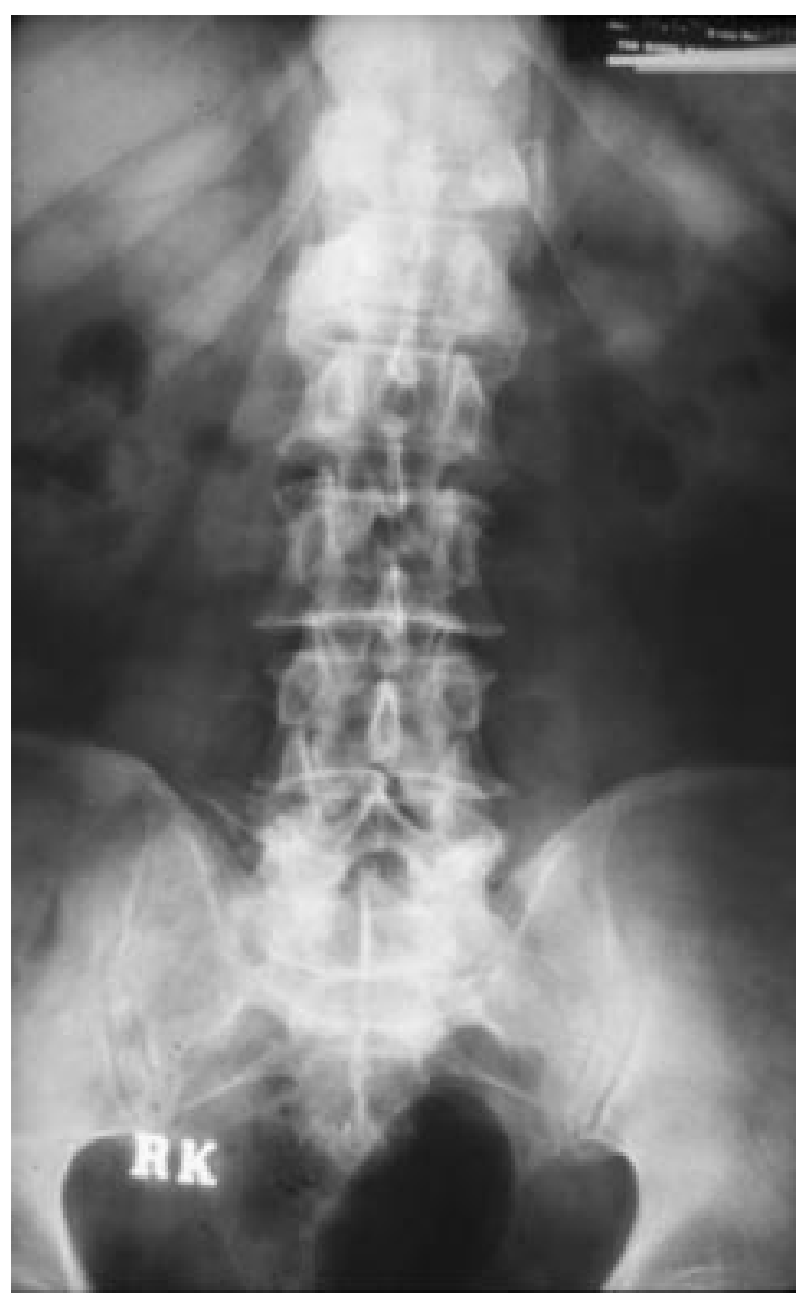

Figure 7 Radiograph (anterior view) of the lumbar spine in diffuse idiopathic skeletal hyperostosis.

\section{Carpal tunnel syndrome}

Carpal tunnel syndrome (CTS) is a disorder characterised by paraesthesia over the median nerve cutaneous distribution of the thumb, index, middle, and lateral half of the ring fingers, which is often worse at night. The symptoms may be caused by compression of the median nerve within the carpal tunnel, diabetic neuropathy, or a combination of both. ${ }^{24}$ CTS is common in patients with diabetes, with an estimated prevalence of $11-16 \%$, ${ }^{25}$ compared with an incidence of about 125 per 100000 population over a five year period. ${ }^{27}$ About $5-8 \%$ of patients with CTS have diabetes ${ }^{28}$ CTS is more common in women than in men. Associations between carpal tunnel syndrome and age and the duration of diabetes have been suggested.$^{24}$ Treatment of CTS consists of the use of simple analgesics, splints, and possibly local steroid injections for the milder cases of compressive CTS. Surgery is indicated in those patients who fail the above conservative measures.

\section{Flexor tenosynovitis}

Flexor tenosynovitis (trigger finger or stenosing tenovaginitis) is caused by fibrous tissue proliferation in the tendon sheath leading to limitation of the normal movement of the tendon. The prevalence of flexor tenosynovitis is estimated at $11 \%$ in diabetic patients, compared with $<1 \%$ in non-diabetics. ${ }^{29}$ There is also an increased incidence in people with impaired glucose tolerance. ${ }^{30}$ Flexor tenosynovitis is associated with the duration of diabetes but not age. ${ }^{29}$ A corticosteroid injection into the symptomatic flexor tendon sheath is often curative. 


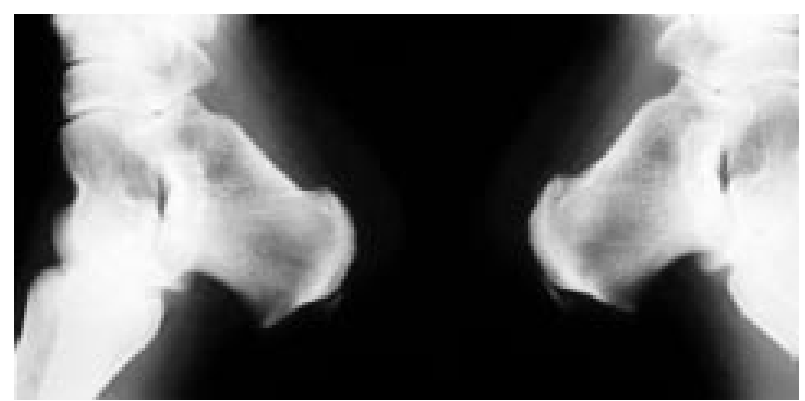

Figure 8 Bilateral calcified Archilles tendons in a patient with diabetes.

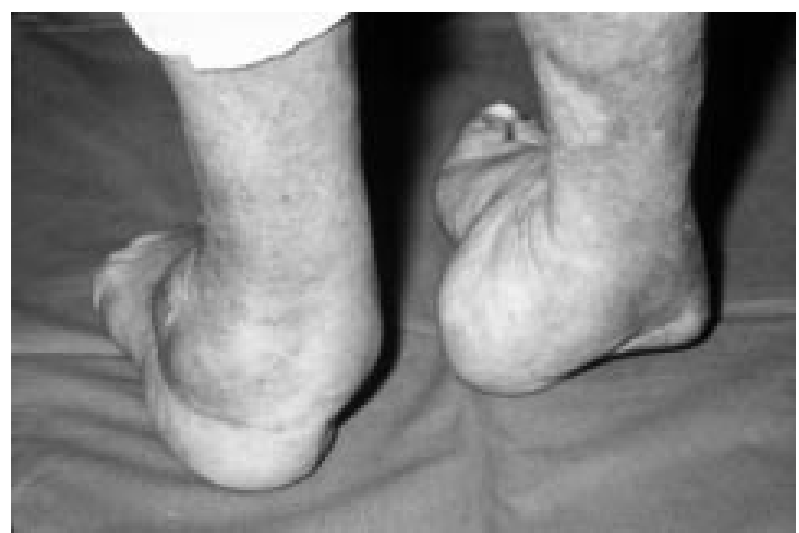

Figure 9 Joint destruction such as is seen in Charcot's disease.

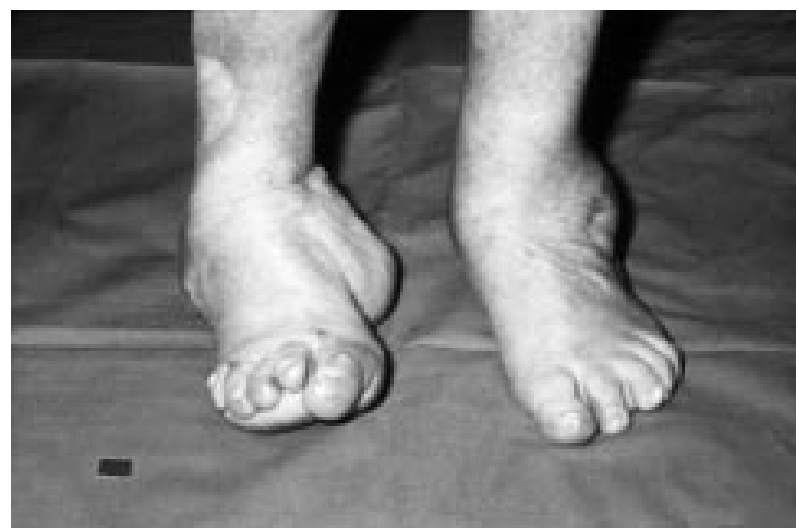

Figure 10 Joint destruction such as is seen in Charcot's disease.

\section{Reflex sympathetic dystrophy}

Reflex sympathetic dystrophy is also known as algodystrophy, Sudeck's atrophy, and chronic regional pain syndrome type 1. It is characterised by localised or diffuse pain, usually with associated swelling, trophic changes, and vasomotor disturbances, ${ }^{31}$ with impaired mobility of the affected region (figs 4 and 5). There have been difficulties with the definitions of reflex sympathetic dystrophy, and the cause, pathogenesis, and natural history are unclear. The condition may occur spontaneously, or after minimal trauma-following surgery or a fracture. Concurrent medical conditions may predispose to reflex sympathetic dystrophy, including diabetes mellitus, hyperthyroidism, hyperparathyroidism, and type IV hyperlipidaemia. ${ }^{32}$ A variety of treatments have been used with anecdotal success, including analgesics, physiotherapy, intravenous bisphosphonates, calcitonin, oral corticosteroids, and sympathetic ganglion blocks. ${ }^{32}$ The outcome is usually good, although some patients develop chronic pain and contractures.

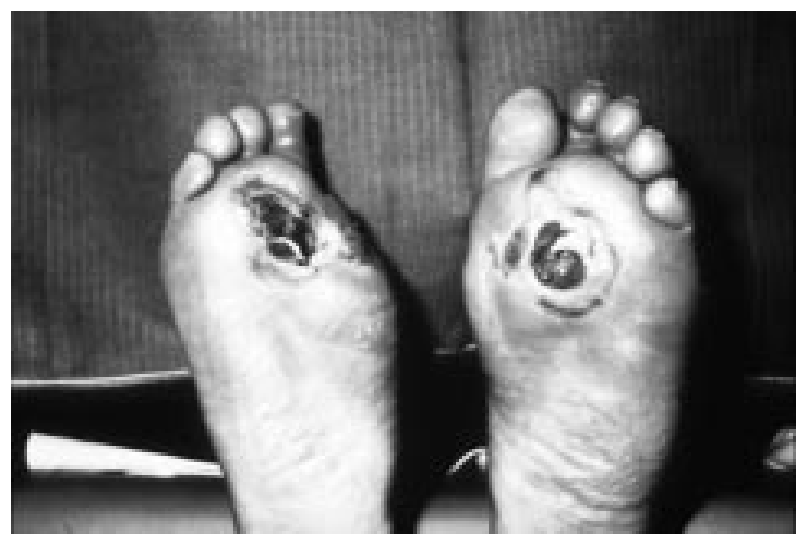

Figure 11 Bilateral painless ulcers in a patient with diabetic peripheral neuropathy.

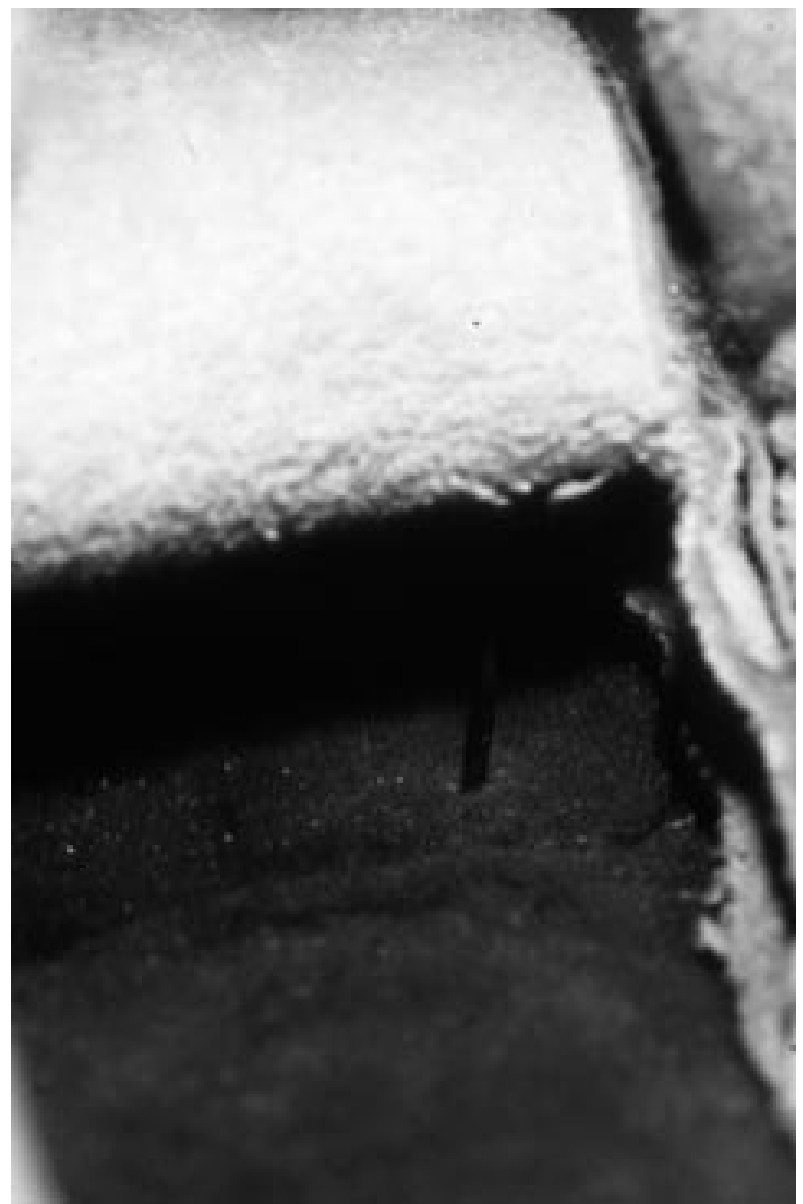

Figure 12 The nail through the sole of this slipper (see arrow) worn by a patient with diabetic peripheral neuropathy, was only noticed at the end of the day when the slipper was romoved.

\section{DIFFUSE IDIOPATHIC SKELETAL HYPEROSTOSIS}

Diffuse idiopathic skeletal hyperostosis, also known as ankylosing hyperostosis or Forestier's disease, is characterised by new bone formation, particularly in the thoracolumbar spine (figs 6 and 7). New bone appears to "flow" from one vertebra to the next, and is more prominent on the right side of the thoracic vertebra. ${ }^{33}$ Ossification of ligaments and tendons elsewhere may occur, such as the skull, pelvis, heels, or elbows $^{15}{ }^{34}$ (fig 8). A proposed mechanism of causation is the prolonged and high levels of insulin or insulin-like growth factors occurring in diabetic patients, stimulating new bone 


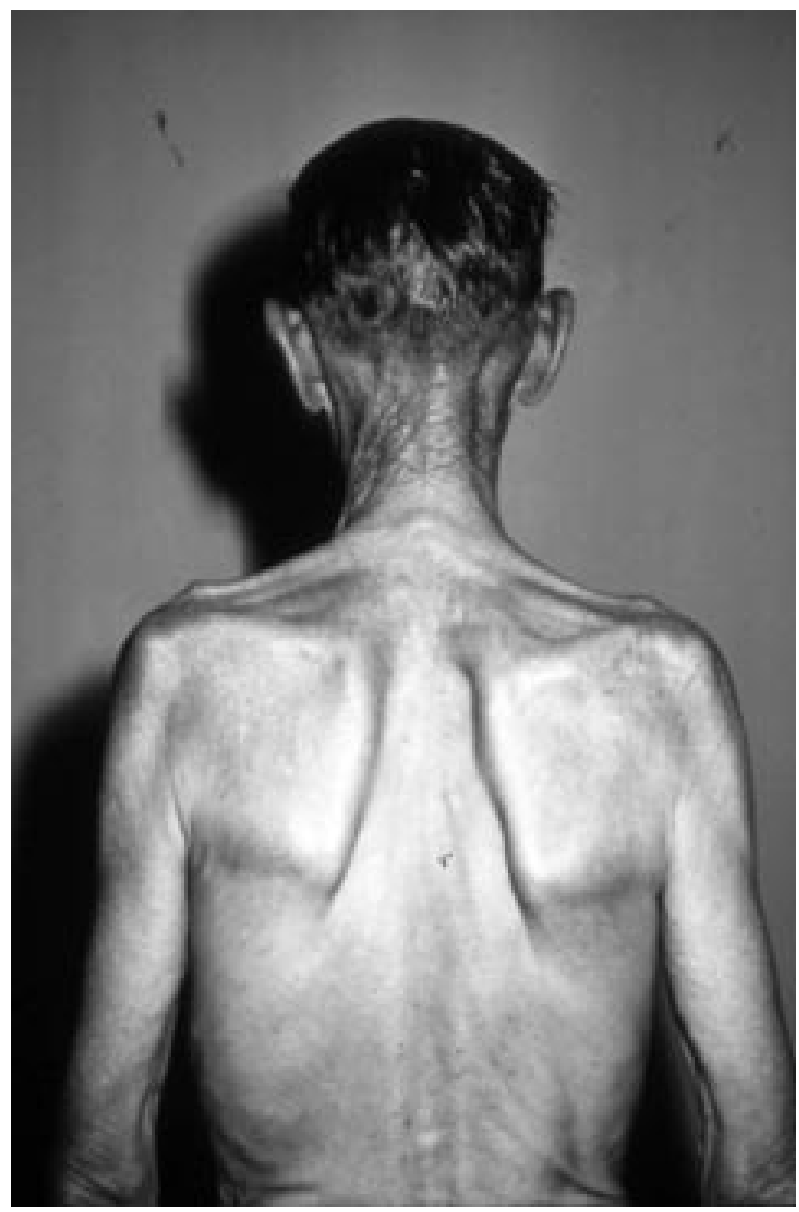

Figure 13 Diabetic amyotrophy of the shoulder girdle.

growth, and may explain the higher prevalence in type 1 compared with type 2 diabetes (ratio 3:1). ${ }^{20}$ There may be associated pain in one third of patients who have hyperostosis of the heels or elbows. Patients with hyperostosis of the spine may have associated mild stiffness on arising in the morning, and $16 \%$ of affected persons may develop dysphagia. ${ }^{14}$ In most cases affected persons have normal mobility of the spine and may be asymptomatic, with the diagnosis of the condition an incidental radiographic finding. ${ }^{15}$ Estimated prevalence is $13-49 \%$ in diabetic patients ${ }^{6}$ and $1.6-13 \%$ in non-diabetics. ${ }^{20}$ Among patients with diffuse idiopathic skeletal hyperostosis, $12-80 \%$ have diabetes or impaired glucose tolerance. The high prevalence of abnormal glucose tolerance tests in patients with diffuse idiopathic skeletal hyperostosis is partly a result of an association with obesity, with $83 \%$ of patients being male and $30 \%$ obese.$^{14}$ Obesity and diabetes seem to have independent contributions to the development of the condition. ${ }^{14}$

Rates of hyperostosis increase with age in both the normal and diabetic populations, although the age related increase in incidence begins earlier in diabetics. ${ }^{6}$ Management consists of education, diabetic control, and physiotherapy.

\section{NEUROPATHIC (CHARCOT'S) JOINTS}

Charcot's disease, or joints, is a result of diabetic peripheral neuropathy. A reduction in the normal afferent protective neural impulses, and therefore loss of protection from trauma to the joint leads to progressive, painless joint destruction (figs 9 and 10). Charcot's joints are typically seen in patients over the age of 50 who have had diabetes for many years and have existing neuropathic complications (figs 11 and 12). The joints most commonly affected are weight-bearing joints such as the foot, ankles, and knees; joints such as the hand and wrist are rarely affected. ${ }^{35}$ Initial warmth and erythema mimic osteomyelitis or septic arthritis, but the absence of fever, elevated white cell count, and elevated erythrocyte sedimentation rate helps to differentiate the latter two conditions. Management consists of optimising glycaemic control and regular foot care and review, particularly in those with grossly impaired sensation. The use of orthotics and crutches can relieve pressure on the affected joints during ambulation. ${ }^{35}$ Occasionally surgery may be required if complicated fractures develop.

\section{DIABETIC AMYOTROPHY}

Diabetic amyotrophy is a disabling illness that is distinct from other forms of diabetic neuropathy. It is characterised by muscle weakness and wasting, and by diffuse, proximal lower limb muscle pain, and asymmetrical loss of tendon jerks. The shoulder girdle may be affected, but less commonly (fig 13). It typically occurs in older men with type 2 diabetes, and is often associated with weight loss, sometimes as much as $40 \%$ of premorbid body mass. The exact cause and incidence of diabetic amyotrophy is uncertain. It is a diagnosis of exclusion: sinister causes must be sought and excluded because of the clinical picture of weight loss and new neurological signs. Management consists of stabilising glycaemic control and use of physiotherapy. Most cases improve, but the improvement is gradual and often incomplete. ${ }^{36}$

\section{CONCLUSION}

The complications of diabetes mellitus are numerous and include involvement of the musculoskeletal system. Several rheumatic conditions are more prevalent or caused by the long term metabolic consequences of diabetes mellitus. When the control of diabetes is poor, higher levels of diabetic complications result. ${ }^{3}$ Poor glycaemic control can lead to worsening of certain rheumatic conditions. Pharmacotherapy, diet, and a regular, sensible physiotherapy programme should be the cornerstone of diabetes management. It is our recommendation that all patients with diabetes have an appropriate exercise programme, overseen by their medical practitioner, as an integral part of their diabetes management in order to reduce the frequency and severity of complications.

\section{ACKNOWLEDGEMENTS}

This research was supported by a grant from the Modbury Hospital Foundation.

\section{Authors' affiliations}

L L Smith, S P Burnet, J D McNeil, Department of Medicine, University of Adelaide, Adelaide, Australia

\section{REFERENCES}

1 Dunstan D, Zimmet P, Welborn T, et al. Diabesity and associated disorders in Australia 2000; Australian diabetes, obesity and lifestyle report (Ausdiab). Melbourne: International Diabetes Institute, 2001.

2 Joslin EO, Root EF, White P. The treatment of diabetes mellitus. Philadelphia: Lea \& Febiger, 1959.

3 The effect of intensive treatment of diabetes on the development and progression of long-term complications in insulin-dependent diabetes mellitus. The Diabetes Control and Complications Trial Research Group. N Engl J Med 1993;329:977-86.

4 Boule NG, Haddad E, Kenny GP, et al. Effects of exercise on glycemic control and body mass in type 2 diabetes mellitus: a meta-analysis of controlled clinical trials. JAMA 2001;286:1218-27.

5 Reeves B. The natural history of the frozen shoulder syndrome. Scand J Rheumatol 1975:4:193-6.

6 Forgács SS. Endocrine and hemoglobin arthropathies: diabetes mellitus. Rheumatology. London: Mosby-Year Book Europe Ltd, 1994.

7 Griggs SM, Ahn A, Green A. Idiopathic adhesive capsulitis. A prospective functional outcome study of nonoperative treatment. J Bone Joint Surg [Am] 2000;82:1398-407

8 Bridgman JF. Periarthritis of the shoulder and diabetes mellitus. Ann Rheum Dis 1972;31:69-71.

9 Lequesne $M$, Dang N, Bensasson $M$, et al. Increased association of diabetes mellitus with capsulitis of the shoulder and shoulder-hand syndrome. Scand J Rheumatol 1977;6:53-6. 
10 Balci N, Balci MK, Tuzuner S. Shoulder adhesive capsulitis and shoulder range of motion in type II diabetes mellitus: association with diabetic complications. J Diabetes Complications 1999;13:135-40.

11 Arkkila PE, Kantola IM, Viikari JS, et al. Shoulder capsulitis in type I and II diabetic patients: association with diabetic complications and related diseases. Ann Rheum Dis 1996;55:907-14.

12 Gamstedt A. Hand abnormalities in patients with NIDDM. Prog Diabetes $1993 ; 4: 1-6$

13 Buckingham BA, Uitto J, Sandborg C, et al. Scleroderma-like changes in insulin-dependent diabetes mellitus: clinical and biochemical studies. Diabetes Care 1984:7:163-9.

14 Rosenbloom A. Connective tissue disorders in diabetes. International textbook of diabetes mellitus. 2nd ed. Chichester: John Wiley, 1997:1517-31.

15 Crisp AJ, Heathcote JG. Connective tissue abnormalities in diabetes mellitus. J R Coll Physicians Lond 1984;18:132-41.

16 Jennings AM, Milner PC, Ward JD. Hand abnormalities are associated with the complications of diabetes in type 2 diabetes. Diabet Med 1989;6:43-7.

17 Starkman HS, Gleason RE, Rand LI, et al. Limited joint mobility (LIM) of the hand in patients with diabetes mellitus: relation to chronic complications. Ann Rheum Dis 1986;45:130-5.

18 Eadington DW, Patrick AW, Frier BM. Association between connective tissue changes and smoking habit in type 2 diabetes and in non-diabetic humans. Diabetes Res Clin Pract 1991;11:121-5.

19 Noble J, Heathcote JG, Cohen H. Diabetes mellitus in the aetiology of Dupuytren's disease. J Bone Joint Surg [Br] 1984;66:322-5.

20 Forgacs SS. Diabetes mellitus and rheumatic disease. Clin Rheum Dis $1986 ; 12: 729-53$

21 Carson J, Clarke C. Dupuytren's contracture in pensioners at the Royal Hospital Chelsea. J R Coll Physicians Lond 1993;27:25-7.

22 Lennox IA, Murali SR, Porter R. A study of the repeatability of the diagnosis of Dupuytren's contracture and its prevalence in the grampian region. J Hand Surg $[\mathrm{Br}] 1993 ; 18: 258-61$.
23 Gudmundsson KG, Arngrimsson R, Sigfusson N, et al. Epidemiology of Dupuytren's disease: clinical, serological, and social assessment. The Reykjavik Study. J Clin Epidemiol 2000;53:291-6.

24 Jung Y, Hohmann TC, Gerneth JA, et al. Diabetic hand syndrome. Metabolism 1971;20:1008-15.

25 Phalen GS. Reflections on 21 years' experience with the carpal-tunnel syndrome. JAMA 1970;212:1365-7.

26 Comi G, Lozza L, Galardi G, et al. Presence of carpal tunnel syndrome in diabetics: effect of age, sex, diabetes duration and polyneuropathy Acta Diabetol Lat 1985;22:259-62.

27 Stevens JC, Sun S, Beard CM, et al. Carpal tunnel syndrome in Rochester, Minnesota, 1961 to 1980. Neurology 1988;38:134-8.

28 Deal C. The endocrine system. Oxford textbook of rheumatology. 2nd ed. Oxford: Oxford University Press, 1998:282-5.

29 Leden I, Schersten B, Svensson B, et al. Locomotor system disorders in diabetes mellitus. Increased prevalence of palmar flexortenosynovitis Scand J Rheumatol 1983;12:260-2.

30 Leden I, Svensson B, Sturfelt $G$, et al. 'Rheumatic' hand symptoms as a clue to undiagnosed diabetes mellitus. Scand J Rheumatol 1980;9:127-8.

31 Kozin F. Reflex sympathetic dystrophy syndrome: a review. Clin Exp Rheumatol 1992;10:401-9.

32 Marshall AT, Crisp AJ. Reflex sympathetic dystrophy. Rheumatology (Oxford) 2000;39:692-5.

33 Lipson S.J. Low back pain. Textbook of rheumatology. 5th ed. Philadelphia: Saunders WB, 1997

34 Bland JH, Frymoyer JW, Newberg AH, et al. Rheumatic syndromes in endocrine disease. Semin Arthritis Rheum 1979;9:23-65.

35 Bayne O, Lu EJ. Diabetic Charcot's arthropathy of the wrist. Case report and literature review. Clin Orthop 1998;357:122-6.

36 Sander HW, Chokroverty S. Diabetic amyotrophy: current concepts. Semin Neurol 1996:16:173-8.

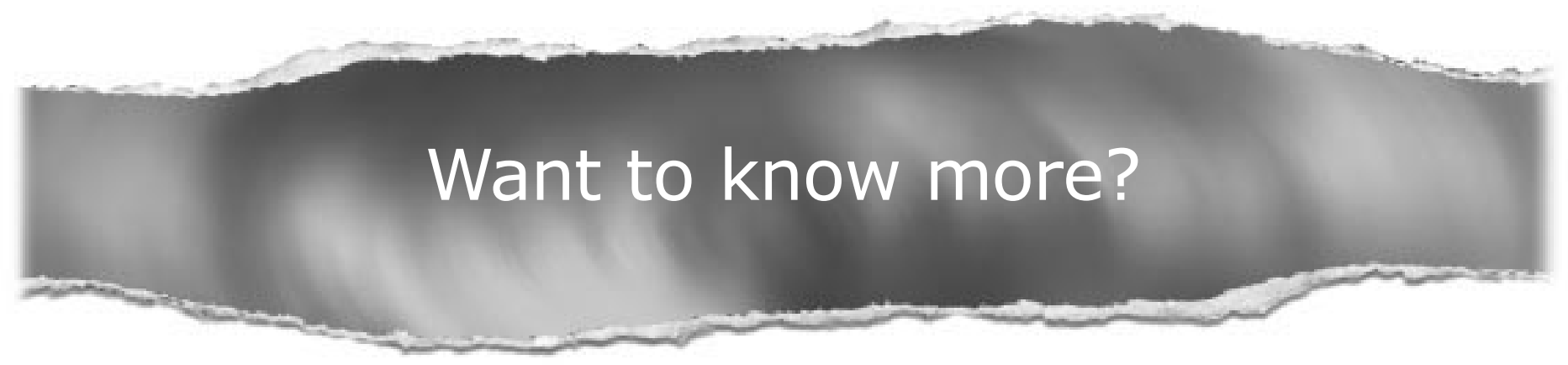

Data supplements

Limited space in printed journals means that interesting data and other material are often edited out of articles; however, limitless cyberspace means that we can include this information online.

Look out for additional tables, references, illustrations.

www.bjsportmed.com 